\title{
RETORNO MIGRATÓRIO: GLOBALIZAÇÃO AFETIVA E DESPERTENCIMENTO NO FILME O CÉU DE SUELY
}

\section{RETURN MIGRATION: AFFECTIVE GLOBALIZATION AND THE FEELING OF NOT BELONGING IN THE FILM “O CÉU DE SUELY”}

\begin{abstract}
Aline Aparecida de Souza Vaz
RESUMO

O trabalho estrutura-se na correlação cinema e processos migratórios, tendo como objeto de análise o filme $O$ Céu de Suely (AÏNOUZ, 2006). Quando Hermila permanece fixa na paisagem de Iguatu, sem constituí-la em espaço (SANTOS, 1988), não cria vínculos nem identificação e ressignifica sua identidade, não é Hermila e nem Suely, ocupa o deslugar (FISCHER, 2012). Em busca de paisagens transculturais (LOPES, 2012) em que possa atravessar culturas e criar vínculos, precisa estar em trânsito. Busca-se interpretar como o retorno migratório de Hermila, evidencia o despertencimento da personagem que não habita (HEIDEGGER, 1979) de fato a cidade natal, explorando as tessituras fílmicas entre os deslocamentos humanos e as necessidades de partida em busca dos afetos.
\end{abstract}

Palavras-chave: Cinema Migratório; Paisagens; Afetos; Despertencimento.

\begin{abstract}
This article discusses the relationship between cinema and migration processes through the analysis the film $O$ Céu de Suely (KARIM AÏNOUZ; 2006). When Hermila remains fixed on the of Iguatu landscape without turning it into a space (MILTON SANTOS, 1988), she does not create bonds, nor identifies or reframes her identity; she is neither Hermila nor Suely; she occupies the non space (SANDRA FISCHER, 2012). In search of cross-cultural landscapes (DENILSON LOPES, 2012), where she can cross cultures and create links, she needs to be in transit. The aim of this study is to interpret how the return migration of Hermila shows the feeling of not belonging of the character that does not in fact live in (HEIDEGGER, 1979) her hometown, exploring how the film presents human displacement and the need of departure in search of affections.
\end{abstract}

Keywords: Migration Cinema; Landscapes; Affections; "not belonging”.

\footnotetext{
“Mestranda pelo Programa de Pós-Graduação em Comunicação e Linguagens da Faculdade de Ciências Sociais Aplicadas da Universidade Tuiuti do Paraná (FCSA-UTP). Especialista em Cinema. Graduada em Letras - Português/Inglês. Pertence aos GPs GRUDES - Desdobramentos Simbólicos do Espaço Urbano em Narrativas Audiovisuais (PPGCOM - UTP) e Cinema - Criação e Reflexão (UNESPAR - FAP).
} 


\section{Introdução}

Do Cinema Novo de Nelson Pereira dos Santos (Vidas Secas, 1963), que retratava um deslocamento migratório em busca de melhores condições econômicas para saciar a fome e a sede, até o cinema da retomada dos anos 90, em que "exibe sua diferença, mas não está preocupado em proclamar rupturas. Privilegia os dados de continuidade" (XAVIER, p. 82), em deslocamentos que buscam um bem social para todo o núcleo familiar, a migração deixa seus rastros e encontra o cinema contemporâneo. No cinema migratório do século XXI, à luz da presente pesquisa, percebe-se a migração em busca de afetos, personagens que se deslocam sozinhos e de fato não percorremos o trajeto com eles, diferente do que víamos em Vidas Secas (SANTOS, 1963). Acompanhamos o lugar de chegada desses personagens, que buscam melhores condições ligadas às subjetividades, por isso chegam e/ou partem sozinhos.

Diante das novas narrativas migratórias, busca-se interpretar como o retorno migratório evidencia o despertencimento da personagem que não habita de fato a cidade natal, explorando as tessituras fílmicas entre os deslocamentos humanos e as necessidades de partida em busca dos afetos. Para tal objetivo, entre a filmografia migratória contemporânea, após levantamento junto às pesquisas relacionadas ao Grupo de Pesquisa Desdobramentos Simbólicos do Espaço Urbano em Narrativas Audiovisuais (Grudes - PPGCOM/UTP), O Céu de Suely (AÏNOUZ, 2006), que narra o intervalo entre a chegada e partida de Hermila no Ceará, onde decide rifar seu próprio corpo para comprar uma passagem de ônibus para o lugar mais longe de Iguatu, torna-se objeto de análise da presente pesquisa, estruturando na correlação cinema e processos migratórios, vínculos em trânsito e a necessidade de deslocamento em busca de pertencimento afetivo entre paisagens, que precisam ser habitadas, imergidas de afetos transculturais.

A análise fílmica de $O$ Céu de Suely se dá por intermédio de frames selecionados que constroem significados por meio do que mostram. A composição poética da imagem que evidencia os deslocamentos da protagonista é analisada a partir de referencial teórico que abrange os não-lugares de Marc Augé (2010) até os deslugares de Sandra Fischer (2012), o ser e estar de Martin Heidegger (1979), as metamorfoses do espaço habitado de Milton Santos (1988), até os modos de habitar transitórios de Denise Moraes Cavalcante (2015), chegando as paisagens transitórias de Denílson Lopes (2012), aos estudos relacionados ao cinema e migração de Rafael Tassi Teixeira (2015) e as resignificações identitárias na pós-modernidade de Stuart Hall (2006). Assim, questiona-se o habitar em paisagens que não pertencem à personagem em trânsito, um estar transitório.

\section{O des/pertencimento do retorno migratório}

Pressupõe-se que "os deslocamentos humanos são uma dimensão importante para a compreensão dos fenômenos subjetivos contemporâneos" (TEIXEIRA, 2015, p. 39). Denilson Lopes (2012), fala de paisagens transculturais, atravessar culturas, criar vínculos e afetos em trânsito. Pertencer não é físico. Estar é criar afetos, constituir imagens e estabelecer vínculos. Hermila, a protagonista do filme $O$ Céu de Suely (AÏNOUZ, 2006), relembra as imagens de Matheus, seu grande amor. Em Super 8 (Figura 1) as imagens da memória transportam a personagem para o domingo de manhã, o dia em que Matheus a pegou pelo braço e disse que a faria a pessoa mais feliz do mundo.

Figura 1 - Frame do filme O Céu de Suely - Imagens afetivas em Super 8

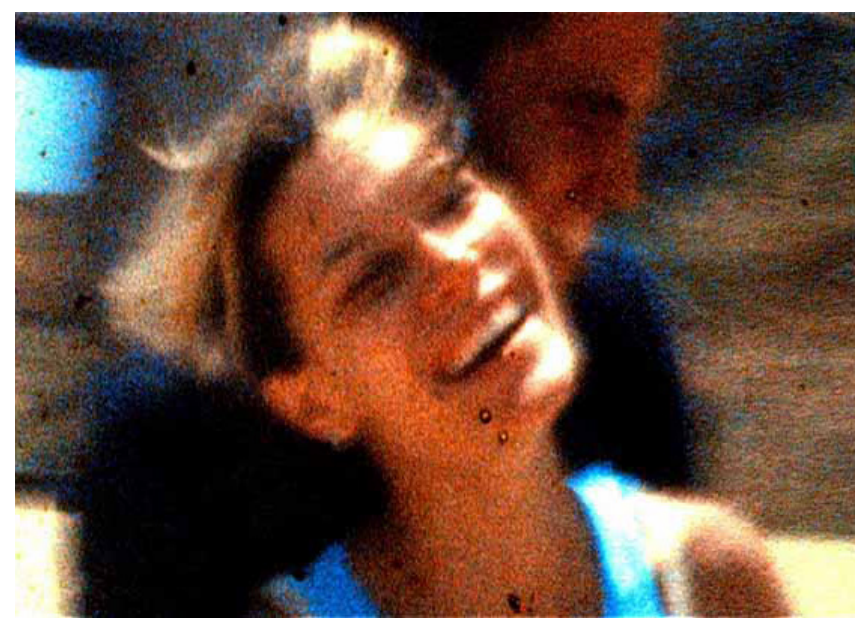

Em um cenário de globalização, aqui entendida como um processo multifacetado que redefine o jogo entre global e local em meio à compressão do tempo e do espaço, formas de sociabilidade se constituem em espacialidades erguidas por experiências fluidas em circuitos de interações comunicativas e 
afetivas. As práticas sociais e as relações interpessoais são afetadas pela estruturação e organização dos espaços e pela maneira de estar no espaço social (CAVALCANTE, 2015, p. 10).

A pequena cidade fílmica de Iguatu, de $O$ Céu de Suely, é globalizada de afetos do cotidiano, dos conflitos que imergem das formas de pertencimento. Onde Hermila pertence? Ao coração de Matheus que não a acolhe mais. Hermila não mora em nenhum lugar, não há espaço para imergir afetos. Ser e estar para Heidegger constitui o compreender e possuir o mundo, em que "ser" "se deriva de sedere, estar sentado. Nós falamos de "residência". Assim se denomina o lugar onde se demora o habitar. Demorar-se é estar presente junto a [...]" (HEIDEGGER, 1979, p. 450). O movimento migratório de transição, o retorno como intervalo, para um novo movimento migratório, não permite que Hermila habite o mundo, pois não se demora.

A nordestina que vai para São Paulo em busca de uma vida melhor, diz que lá era bom, mas viver lá custa caro, foi melhor voltar. O retorno migratório transforma a personagem que não pertence a São Paulo, mas também não é mais de Iguatu. Na paisagem do Ceará, Hermila não diz, mas sim inclui o que sente, "que parte de uma indeterminação e que utiliza a incoerência e aquilo que não pode ser imediatamente exposto como a lógica ou motivo da experiência: estas existem apenas nos imaginários mais substancialistas da condição da identidade" (TEIXEIRA; FISCHER, 2015, p. 43).

O cabelo com uma mecha loira evidencia as mudanças que ocorreram no trânsito da personagem. A tia questiona: “é moda por lá?” João diz que ela está diferente, também fala da mecha. Em Iguatu nem a aparência de Hermila é mais reconhecida.

[...] proliferam-se filmes em que a cidade e seus habitantes aparecem como protagonistas mobilizados pelas dinâmicas da globalização, mediando imagens de imigrantes, cosmopolitas, expatriados, mas também espreitados, desamparados, deslocados que deambulam, trafegam, circulam de carro, de metrô, a pé em ruas, avenidas, edifícios, aeroportos, postos de gasolina, hotéis e casas (CAVALCANTE, 2015, p. 13).

Ao chegar à cidade natal a protagonista espera a tia em um posto de gasolina, esse não-lugar em que o sujeito está de passagem,
[...] instalações necessárias à circulação acelerada das pessoas e bens (vias expressas, trevos rodoviários, aeroportos) quanto os próprios meios de transporte ou os grandes centros comerciais, ou ainda os campos de trânsito prolongado onde são estacionados os refugiados do planeta" (AUGÉ, 2010, p. 35).

A personagem chega de passagem por Iguatu. "O espaço do não-lugar não cria nem identidade singular nem relação, mas sim solidão e similitude" (AUGÉ, 2010, p. 94). De fato, Hermila está sozinha, sem identificação com o local, não está e não é, torna-se Suely, aquela que precisa ir para longe, buscar paisagens afetivas. "Chega-se, mas não se vive" (TEIXEIRA, 2015, p. 48), ficar é a morte de Hermila.

Desse modo, Hermila está em deslugar, faz o processo migratório de retorno, mas é assolada pelo desconforto e estranhamento que encontra no seu lugar que não é mais.

[...] é alguém que não está dentro, não está fora, não está entre dentro e fora; que não pertence pertencendo e que pertence sem pertencer; alguém que é mas não é. O sujeito pode, preenche todas as condições que lhe facultam ocupar determinada posição, mas a ela não se acomoda. É o ser sem ser. (FISCHER, 2012, p. 04)

Se Hermila não pertence a São Paulo e não se sente mais em Iguatu, deixa de ser Hermila, mas também não é Suely, no qual o pertencimento é transportado "para o âmbito psíquico-intelecto-emocional das relações humanas em seus desdobramentos sócio-afetivo-amorosos" (FISCHER, 2012, p. 03).

\section{O lugar do afeto identitário}

As identidades culturais que, para Stuart Hall (2006), surgem de nosso pertencimento são deslocadas e fragmentadas no fluxo globalizante. As mudanças estruturais "estão também mudando nossas identidades pessoais, abalando a ideia que temos de nós próprios como sujeitos integrados" (HALL, 2006, p. 09), acarretando na perda do "sentido de si" estável. As identidades estão em deslocamento, descentradas do sujeito.

A formação do eu no "olhar" do Outro, de acordo com Lacan, inicia a relação da criança com os sistemas simbólicos fora dela mesma e é, assim, o momento da sua entrada nos vários sistemas de re- 
presentação simbólica - incluindo a língua, a cultura e a diferença sexual (HALL, 2006, p. 37-38).

Ao olhar para o outro e ver-se no olhar desse outro ocorre uma identificação. Ao olhar para a cidade de Iguatu e não se ver nela, Hermila não se identifica, ressignifica sua identidade, já que ela constitui-se pelo o que está dentro de nós e também por preenchimentos externos.

Para Stuart Hall (2006, p. 81), "as pessoas mais pobres do globo, em grande número, acabam por acreditar na 'mensagem' do consumismo global e se mudam para locais de onde vêm os 'bens' e onde as chances de sobrevivência são maiores". Hermila vai para São Paulo em busca desses "bens", mas como não pode consumi-los volta para a pequena cidade do Ceará, mas lá percebe que também não consome essa cidade, decepciona-se.

As transições migratórias "não são e nunca serão unificadas no velho sentido, porque elas são, irrevogavelmente, o produto de várias histórias e culturas interconectadas, pertencem a uma e, ao mesmo tempo, a várias 'casas' (e não a uma 'casa' particular)" (HALL, 2006, p. 88 - 89).

É justamente nessas várias casas que se prenuncia o despertencimento. "A casa é nosso canto do mundo" (BACHELARD, 1978, p. 200). Quando temos várias casas acabamos por não ter nenhuma, não encontramos o canto no mundo, não nos encolhemos. "Só mora com intensidade aquele que já soube encolher-se" (BACHELARD, 1978, p. 197).

A casa, na vida do homem, afasta contingências, multiplica seus conselhos de continuidade. Sem ela, o homem seria um ser disperso. Ela mantém o homem através das tempestades do céu e das tempestades da vida. Ela é corpo e alma. É o primeiro mundo do ser humano. Antes de ser "atirado ao mundo", como o professam os metafísicos apressados, o homem é colocado no berço da casa. E sempre, em nossos devaneios, a casa é um grande berço. Uma metafísica concreta não pode deixar de lado esse fato, esse simples fato, na medida em que esse fato é um valor, um grande valor ao qual voltamos em nossos devaneios. O ser é imediatamente um valor. A vida começa bem; começa fechada, protegida, agasalhada no seio da casa (BACHELARD, 1978, p. 201).

Hermila está dispersa atirada num mundo de idas e vindas, movimentos que não protegem, que a expõe às tempestades do céu e às tempestades da vida. Sem a ilusão de estabilidade, constituída pela casa, não pode proteger seus sonhos. Sem canto no mundo, Hermila migra e busca-se.

\section{As paisagens de Hermila}

Espaço e paisagem que se complementam e se opõem, criam tensão em $O$ Céu de Suely.

[...] a paisagem é diferente do espaço. A primeira é a materialização de um instante da sociedade. Seria, numa comparação ousada, a realidade de homens fixos, parados como numa fotografia. O espaço resulta do casamento da sociedade com a paisagem. O espaço contém o movimento (SANTOS, 1988, p. 72).

A vida no espaço existe, ele é habitado, a paisagem é o passado, imagens de uma personagem parada em uma fotografia em Iguatu, que não se sente afetada pela imagem, precisa sair em busca de um espaço, movimento.

No filme de Karim Ainouz, a protagonista, mulher, nordestina, 21 anos, com um filho nos braços e abandonada pelo grande amor, retorna de São Paulo para Iguatu. O retorno é apenas físico, algo ficou no caminho da transição. A Hermila que foi não é aquela que volta e também não é aquela que se tornou em São Paulo.

"A migração de retorno toma cada vez mais importância no contexto das migrações interestaduais, face à nova dinâmica e padrões migratórios emergentes" (CUNHA, 2000, p. 01). Esses migrantes que retornam não são mais os mesmos, eles voltam modificados pelas experiências, pelas paisagens que deixaram, pelas paisagens as quais retornam, mas nenhuma paisagem é igual, elas são afetadas pelo olhar, "seria, portanto como um espaçamento tramado do olhante e do olhado, do olhante pelo olhado" (DIDIHUBERMAN, 2010, p. 147), nunca será o que já foi, pois as paisagens são afetivas, o olhar afetado pelos vínculos que ficaram, que foram, que não são, que serão.

Longe das situações desesperadas da seca culminando em morte ou em impossibilidade de volta, ruptura radical com a origem, em "Céu de Suely", a experiência migratória, sem pretensão alegórica, é tradução afetiva do trânsito entre culturas, em que a vivência íntima é central (LOPES, 2006, s/p). 
Hermila chega ao seu retorno em Iguatu na solidão da estrada, em que ninguém fica, todos vão ou voltam. No enquadramento da estrada (Figura 2), os viajantes que descem do ônibus com ela logo desaparecem. A protagonista permanece, apequenada pelo sertão, anônima na árida paisagem.

Figura 2 - Frame do filme O Céu de Suely - Hermila apequenada na paisagem

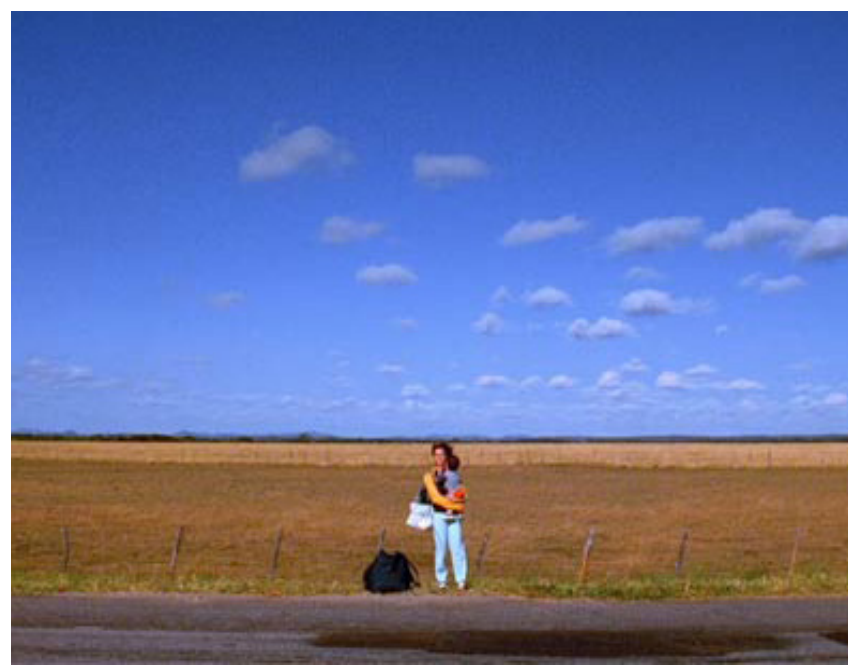

Espaços de não-lugares (Figura 3), a estrada, o posto de gasolina, um céu azul dando a impressão de novo horizonte e o chão seco, marrom, a rigidez do sertão que trilha os passos sofridos dos caminhantes que buscam o céu, o céu de Suely, de João, de Miguel, que buscam o paraíso perdido em paisagens não habitadas. Apequenada pelo sertão, a personagem carrega o filho em um braço e a bagagem em outro, fragmentos da vida que tenta levar consigo.

Figura 3 - Frame do filme O Céu Suely - Hermila no nãolugar

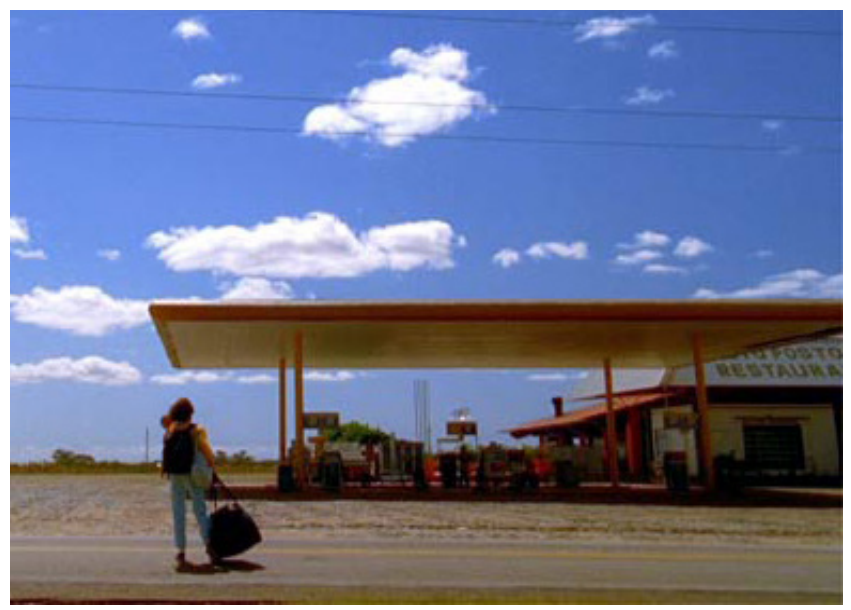

A protagonista está presa em não-lugares, ela vai para a rodoviária em busca de Matheus que não chega. Ela também não vai. Com uma mochila, como se estivesse de partida, permanece na cidade sem estar (Figura 4). O anonimato assegurado pelos não-lugares ressignifica a identidade de Hermila, que não cumpre o contrato de passagem, não é identificada por um cartão de embargue, uma carteira de identidade, um passaporte, ela não é ninguém, nem Hermila, nem Suely.

Figura 4 - Frame do filme O Céu de Suely - Hermila não cumpre o contrato de passagem

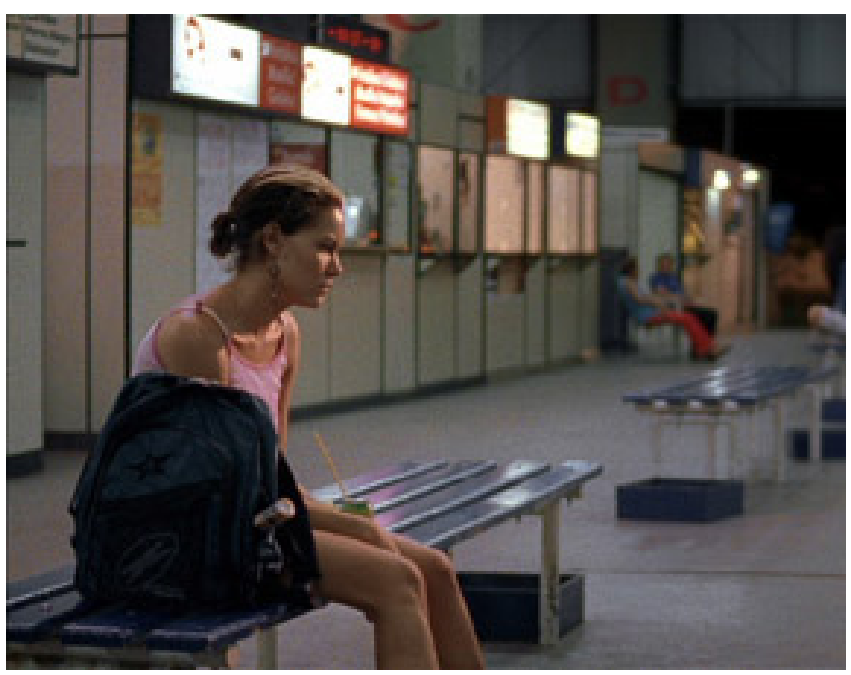

No hotel em que se encontra com João, Hermila também não é Hermila. No hotel em que se encontra com o ganhador da rifa Hermina não é Suely. Quando Hermila vende a rifa para uma noite no paraíso com Suely, ela assume uma nova identidade que poderá levá-la para longe. A rifa irá pagar a passagem para o Rio Grande do Sul, Santa Catarina ou Paraná, não importa desde que seja longe. Sabemos que Hermila desloca-se por amor, Suely desloca-se no espaço do prazer. Ao atravessar esses sentimentos que se ligam como pontes, mas também são fronteiras “[...] sem a construção do amor romântico, retraem suas possibilidades de prazer. Hermila continuaria ligada a sua antiga paixão" (SOUZA, 2011, p. 152). A Hermila não habita as paisagens de Suely, que não habita as paisagens de Hermila.

Pensar a paisagem implica um lugar do sujeito, um posicionamento entrado esse olhar que se estabelece com a perspectiva que emerge no Renascimento e se desdobra até o teatro naturalista. Ir além do 
humanismo é por certo ir além da representação, ir além da paisagem? Se num primeiro momento, confirmamos a tese de Joachim Ritter de que a "emergência do sentimento estético da natureza como paisagem nasce da separação entre homem e natureza (RITTER, 1997, p. 10), foi a partir do Romantismo que a natureza "se mostra a um ser que a contempla vivenciando sentimentos" (RITTER, 1997, apud LOPES, 2014, p. 06).

A paisagem urbana torna-se espaço de habitação da memória, quando a personagem não imerge mais nos vínculos afetivos do local, ela não habita, não pertence. "Não se trata de representar a cidade, intervir na cidade, caminhar pela cidade. Entramos nas sensações e nada mais. É a sensação que importa, que invade, que possui" (LOPES, 2014, p. 08).

Viver num espaço é movimentar-se nas sensações imergidas dele. João não quer deixar a cidade, está confortável, movimenta-se por ela. "Praticar um espaço é percorrê-lo e apropriá-lo em operações de demarcação. Quem caminha não apenas observa a paisagem, reforça as marcas do trajeto ou fixa seus próprios traços (CAVALCANTE, 2015, p. 98-9). Em sua moto pode partir, mas permanece, no espaço que percorre fixa-se. Ele dá carona para Hermila, mas não a leva para outro lugar, a estrada que pode significar partida, não segue a direção do sol, Hermila dá as costas para o céu (Figura 5). Com João ela continua em Iguatu, onde ele pertence, ela talvez tenha pertencido, mas agora des-pertence, como um desligar-se, ao fugir para São Paulo tornou-se desplugada da cidade a qual antes pertencia, ou talvez nunca pertencera de fato.

Figura 5 - Frame do filme O Céu de Suely - A estrada não cumpre o trânsito de partida

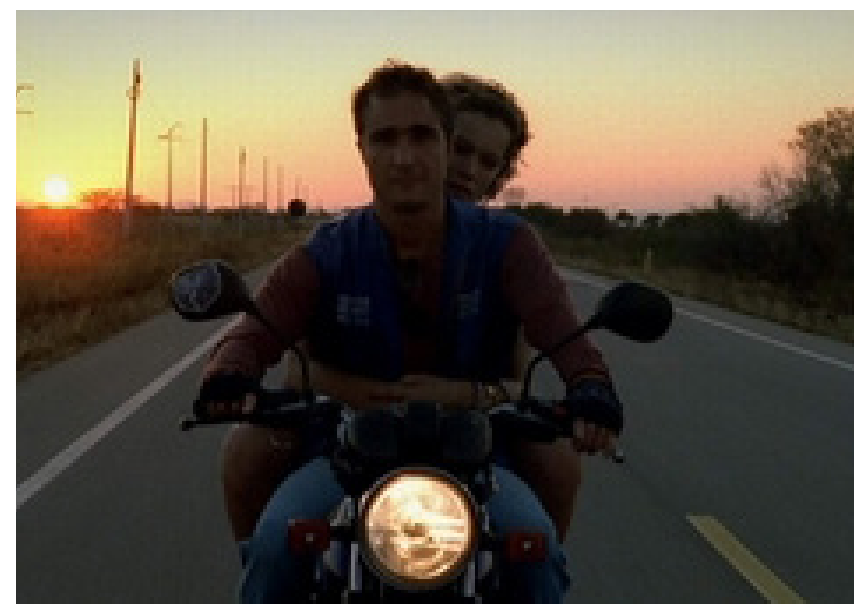

O prefixo "des" admite uma margem para pensar o habitar em um caminho de negação, um "des-habitar" [...] O sentido de desterritório é uma ausência de território, não no sentido de perda de domínio, mas na falta de um vínculo entre espaço e sujeito, em um estado de "des-pertencimento" (CAVALCANTE, 2015, p. 83).

No deslugar Hermila não se identifica com a paisagem, não compreende, não possui, des-habita a cidade. A casa da avó apenas recolhe, sem acolher. $\mathrm{Na}$ primeira noite do retorno o filho chora dentro da casa, acolhido ela ouve o choro no lado externo, ignorando a presença da casa, do choro, do pertencimento à família, do filho que irá pertencer àquela casa sem ela. "Não é, tampouco, exclusividade do âmbito familiar; mas, talvez, uma de suas fontes de origem seja a família: é nesse contexto, parece, que o deslugar tende a instalar-se preferencialmente" (FISCHER, 2012, p. 04).

A casa "deixa de ser pensada como um espaço cultural, habitável, para assumir-se como transitória - mais uma instância de despertencimento, um abrigo, do que propriamente um lar" (VIEIRA, 2010, p. 277). No vão do corredor externo da casa, Hermila encontra-se atravessada (Figura 6), deitada sinaliza cansaço, em algum momento irá levantar-se e partir por esse vão do corredor que evidencia o lugar da casa como transitória. A migração de retorno é um intervalo.

Figura 6 - Frame do filme O Céu de Suely - A casa é transitória

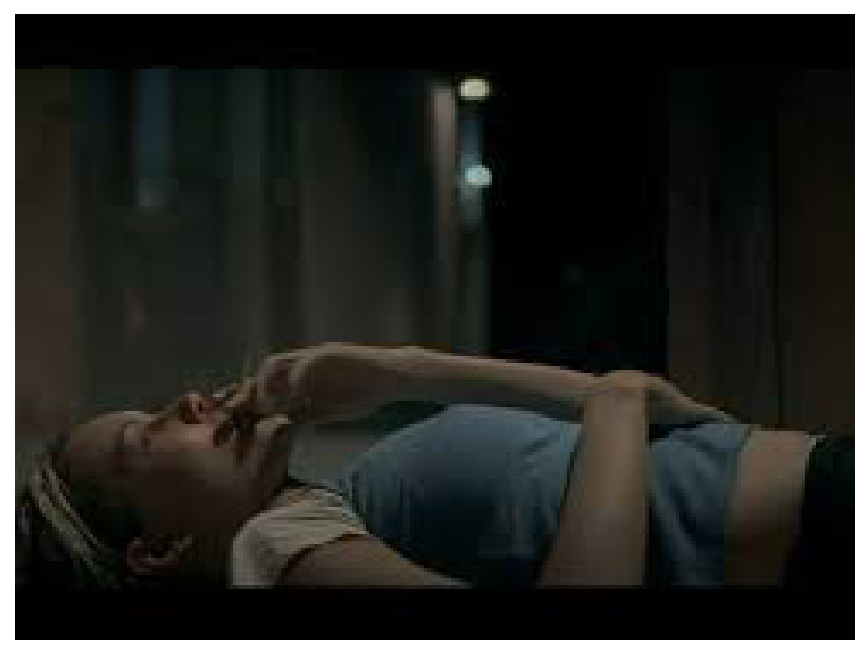

No filme de Aïnouz a personagem em conflito interno conflita com a cidade de Iguatu, que "não 
mais concebida como espaço de estabelecimento de profundos laços de construção identitária, cabe à cidade servir como cenário da experiência do transitório" (VIEIRA, 2010, p. 277).

$\mathrm{Na}$ experiência com o espaço local, com o cotidiano dos afetos e desafetos, Hermila busca uma identificação em busca de identidade, que não está no retorno migratório, é preciso retornar para longe em uma nova experiência como "possibilidade continuada para o estímulo da transformação realizável e da manutenção desejada nas estruturas psíquicas quando elas permitem aos sujeitos acomodarem suas aspirações de vida" (TEIXEIRA, 2015, p. 39).

\section{Aqui começa o afeto}

Se a paisagem é o passado, mesmo que recente, a busca pelo espaço é o movimento entre fixos e fluxos. "A forma de vida do homem é o processo de criação do espaço" (SANTOS, 1988, p. 88). Espaço mutável, ação do homem, o viver do homem que se constitui pelas perspectivas de um futuro habitável.

O espaço de Hermila vai ser habitado em algum lugar longe de Iguatu. Ela cumpre sua passagem na cidade que constitui o despertencimento e agora inicia uma nova viagem em busca de uma paisagem que se torne espaço.

Em uma atitude generosa deixa o filho encontrar seu próprio canto no mundo na casa da avó. Quem vive em deslugar é Hermila, a partida é solitária, "as paixões são curtidas na solidão. É fechado na sua solidão que o ser de paixão prepara suas explosões ou suas façanhas" (BACHELARD, 1978, p. 203).

Em Iguatu Hermila deixa a saudade. Na saudade vive-se o que não mais nos pertence, tudo que passou e deixou de ser. "Não se trata de negar as relações tradicionais de proximidade e vizinhança, mas pensar a nossa sociabilidade como também constituída por 'comunidades de sentimento transnacional' (APPADURAI, 1996, apud LOPES, 2006, p. 11).

A personagem não nega sua tradição, sua cidade local, ela busca afetos que foram desfeitos em Iguatu, onde se pretendia viver com Matheus, mas só pode ter João, que só pode ter Hermila despertencida, ela não pertence a ele, não pertence à Iguatu, ela só ficará com ele, só ficará em Iguatu enquanto não encontrar o movimento de sua vida.
Quando Hermila inicia a migração para Porto Alegre, pegando a estrada novamente, João não pode alcança-la, ele não pode sair de Iguatu, não pode sentir saudades, está nela como ela está nele, a cidade pertence a João, Hermila nunca irá pertencer.

Se na trilha sonora de Hermila e Matheus a letra diz "Tudo que eu tenho meu bem é você", na trilha sonora de Hermila e João a letra questiona: "Coração, para que se apaixonou, por alguém que nunca te amou, por alguém que nunca vai te amar".

João retorna para Iguatu, para o espectador que nunca atravessou o portal da cidade. É a paisagem para qual podemos olhar. O novo horizonte de Hermila não pode ser habitado por João, nem pelo espectador. $\mathrm{O}$ novo espaço habitado pela personagem é dela e com ela seguirá viagem. Quando João aproxima-se da janela do ônibus, Hermila não o vê, a paisagem de Iguatu já não pertence à linha de seu horizonte.

A placa que indica saudade (Figura 7) enfatiza os lugares como espaço de afetividade globalizante, em que deslocar-se é parte constituinte de pertencimentos. "Para os que se retiram ou se deslocam esses lugares se transformam ao longo dos anos em lugares da memória, da saudade, da perda ou das transfigurações identitárias" (MAGNO; GOSCIOLA, 2011, s/p).

Figura 7 - Frame do filme O Céu de Suely - O deslocamento constitui afetividade

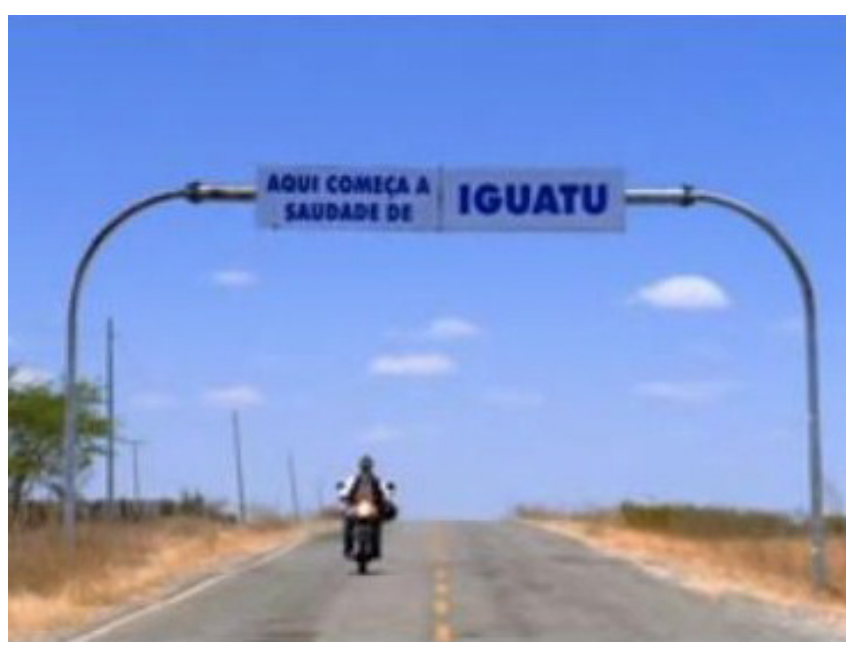

\section{Considerações finais}

Quando se investiga o cinema migratório observa-se "o sertão e suas paisagens como cenários constantes nos filmes que retratam a vida de retirantes ou de sonhadores em direção as cidades grandes" 
(MAGNO; GOSCIOLA, 2011, s/p). No filme O Céu de Suely o movimento é contrário. Percebe-se o retorno migratório como intervalo, na pequena cidade do sertão cearense, entre o que foi e o que será nos deslocamentos humanos e as necessidades de partida em busca dos afetos.

"As identidades retratadas em muitos dos filmes com um viés migratório, no espaço contemporâneo, não negam o passado como um local difícil de ser simultâneo com a lógica do desprendimento e com a absorção da diferença" (TEIXEIRA; FISCHER, p. 44). Filmes que transitam em subjetividades, transitam por sentimentos comuns do cotidiano, personagens que se destacam por seus modos interiores expressos na representação imagética, passeiam por paisagens transculturais. Entre o interno e externo encontra-se o elo que constitui identidades, modos de ser e estar em lugares, olhar para paisagens e habitar espaços.

O cinema, em si, sempre foi uma busca, incompletude perfeitamente em trânsito, movimento identitário que somente se reconhece pelo jogo de características das relações entre culturas, individualidades e possíveis identificações. Ao mostrar como a estruturação psíquica tem profundamente a ver com os contextos simbólicos de onde partem e como eles podem ser fragmentados, guardados, (re) e (des) identificados, o cinema migratório avança nessa característica fundacional (nomadismo emergente) e organiza filmicamente o apêndice da condição contemporânea dos sujeitos emergentes (TEIXEIRA, 2015, p. 39).

No filme de Karim Aïnouz, O Céu de Suely (2006), o retorno migratório evidencia as transformações de uma volta que nunca pode ser preenchida com o que já foi. Apenas a saudade fica. O retorno é sempre marcado de mudanças, transições espaciais de subjetividades imergidas em lugares de idas e vindas. Trata-se de um filme que na subjetividade da personagem alcança o global, pois o mundo pertence aos afetos, "as identidades focalizadas pela busca por uma situação mais condizente com um cenário de intensos cruzamentos, organiza melhor a experiência fílmica dentro de um lócus em que culturas e sociedades são vistas como processos abertos" (TEIXEIRA; FISCHER, 2015, p. 43).

O despertencimento migratório se dá no despertencimento de lugares em que se pode chegar, mas de fato não constitui o habitar. No retorno migratório, a personagem Hermina ocupa o deslugar, fixada em paisagens que se tornam imóveis como uma fotografia. As paisagens não podem permanecer imóveis, devem ir ao encontro do sujeito, tornam-se espaços vivenciados, que só podem ser experimentados pelo sentimento de pertencimento.

As paisagens transculturais de Denílson Lopes (2012) relacionam-se com os vínculos afetivos. $\mathrm{Na}$ Iguatu de Hermila os vínculos são rompidos com a não presença de Matheus, com as transformações que o retorno migratório constitui no olhar de Hermila, ela não olha e também não é olhada com identificação pela cidade. Em Iguatu ela torna-se Suely, é preciso ressignificar sua identidade para que possa sair do lugar de despertencimento. Assim, ela pode ser alguém em outro lugar, pois em Iguatu não é mais.

A música que introduz a narrativa de Hermila é um prenúncio de sua passagem por Iguatu.
Que bom seria ter seu amor outra vez
Você me fez sonhar
Trouxe a fé que eu perdi
E nem eu mesma sei porque
Eu só quero amar você
Tudo que eu tenho meu bem é você
Sem seu carinho eu não sei viver
Tudo que eu tenho meu bem é você
Volte logo meu amor.

Se tudo que ela tinha era Matheus, quando ele se foi ela deixou de ser para tornar-se a espera do que um dia foi?

\section{Referências}

AUGÉ, Marc. Não-lugares. [S. l.]: Papirus Editora, 2010.

BACHELARD, Gaston. Os pensadores. São Paulo: Abril Cultural, 1978.

CAVALCANTE, Denise Moraes. Cinema de ficção contemporâneo e modos de habitar transitórios. Tese (Doutorado em Comunicação)-Universidade de Brasília, Brasília, 2015.

DA CUNHA, Aparecido Soares. Migração de retorno num contexto de crises, mudanças e novos desafios. Rio de Janeiro, ENCE, 2000.

DIDI-HUBERMAN, Georges. O que vemos, o que nos olha. São Paulo: Editora 34, 2010

FISCHER, Sandra. Deslugar e deslocamento em O Palhaço: imagens de transe e trânsito. Revista Interin, v. 12, n. 2, 2012. 
HALL, Stuart. A identidade cultural na pós-modernidade. Rio de Janeiro, DP\&A EDITORA, 2006.

HEIDEGGER, Martin. Conferências e Escritos Filosóficos. Tradução e notas Ernildo Stein. São Paulo: Abril Cultural, 1979. (Os Pensadores, Heidegger).

LOPES, Denílson. Rumo ao Norte: Da Diáspora ao Nomadismo. In: ENCONTRO SOCINE, 10, 2006.

LOPES, Denilson. No coração do mundo: paisagens transculturais. Rio de Janeiro, Rocco, 2012.

LOPES, Denílson. Do entre-lugar ao transcultural. Marina Moguillansky; Andrea, Rio de Janeiro, UFRJ, 2006.

LOPES, Denilson. A Poesia da Luz de Clarissa Campolina, São Paulo, Rebeca, 2014.

MAGNO, Maria Ignês Carlos; GOSCIOLA, Vicente. A construção do imaginário em deslocamento: Um estudo da deslocografia no sertão do cinema brasileiro. Razón y palabra, n. 76, p. 6, 2011.

SOUSA, Sandra Maria Nascimento. Gênero e (des) locamentos: "O céu de Suely". Revista Pós Ciências Sociais, v. 8, n. 16, 2011.

SANTOS, Milton. Metamorfoses do espaço habitado. São Paulo: Hucitec, 1988. v. 4

TEIXEIRA, Rafael Tassi. Alternativas fílmicas na imagem mais recente do olhar sobre a adolescência diaspórica em La jaula de oro (2013). Cinémas d'Amérique Latine, v. 23, p. 38-49, 2015.

TEIXEIRA, Rafael Tassi; FISCHER, Sandra. Diasporismo e anonimidade migratória no cinema: London River. Significação: Revista de Cultura Audiovisual, v. 41, p. 30-47, 2015.VIEIRA, Erly Jr. De passagem: corpos em trânsito nas paisagens urbanas do cinema contemporâneo. In: ENCONTRO SOCINE, 11, 2010.

XAVIER, Ismail. Cinema nacional: táticas para um tempo sem estratégias. Comunicação \& Educação, n. 18, p. 81$86,2000$.

\section{Filmografia}

O Céu de Suely, Karim Ainouz, Portugal, Alemanha, França e Brasil, 2006, 90 min.

Recebido em: 17-07-2015

Aceito em: 07-10-2015 